Review Article

\title{
Bibliometric Analysis of Worldwide Publications on Antimalarial Drug Resistance (2006-2015)
}

\author{
Waleed M. Sweileh, ${ }^{1}$ Samah W. Al-Jabi, ${ }^{2}$ Ansam F. Sawalha, \\ Adham S. AbuTaha, ${ }^{1}$ and Sa'ed H. Zyoud ${ }^{2}$ \\ ${ }^{1}$ Department of Physiology, Pharmacology and Toxicology, College of Medicine and Health Sciences, An-Najah National University, \\ Nablus, State of Palestine \\ ${ }^{2}$ Department of Clinical and Community Pharmacy, College of Medicine and Health Sciences, An-Najah National University, \\ Nablus, State of Palestine
}

Correspondence should be addressed to Ansam F. Sawalha; ansam@najah.edu

Received 28 March 2017; Revised 28 April 2017; Accepted 10 July 2017; Published 10 August 2017

Academic Editor: Sasithon Pukrittayakamee

Copyright (C) 2017 Waleed M. Sweileh et al. This is an open access article distributed under the Creative Commons Attribution License, which permits unrestricted use, distribution, and reproduction in any medium, provided the original work is properly cited.

Background. In response to international efforts to control and eradicate malaria, we designed this study to give a bibliometric overview of research productivity in antimalarial drug resistance (AMDR). Methods. Keywords related to AMDR were used to retrieve relevant literature using Scopus database. Results. A total of 976 publications with an h-index of 63 were retrieved. The number of publications showed a noticeable increase starting in the early 1990s. The USA was the most productive country with 337 publications equivalent to one-third of worldwide publications in this field. More than two-thirds of publications by the USA (236, $70.03 \%$ ) were made by international collaboration. Of the top ten productive countries, two countries were from Mekong subregion, particularly Thailand and Cambodia. The Malaria Journal was the most productive journal (136, 13.93\%) in this field. Mahidol University $(80,8.20 \%)$ in Thailand was the most productive institution. Seven articles in the top-ten list were about artemisinin resistance in Plasmodium falciparum, one was about chloroquine resistance, one was about sulfadoxine-pyrimethamine resistance, and the remaining one was about general multidrug resistance. Conclusion. Eradication and control of AMDR require continuing research activity to help international health organizations identify spots that require an immediate action to implement appropriate measures.

\section{Background}

Malaria is a common and fatal infectious parasitic disease $[1,2]$. It is transmitted through Anopheles mosquitoes [3-6]. It was estimated that 214 million new malaria cases occurred worldwide in 2015 [2]. Malaria control and eradication are one of the major goals of the United Nation's Millennium Development Goals (MDG). In goal number 6, target 6C, the MDG aimed to halt by half and reverse the incidence of malaria by 2015 [7]. This goal was successfully achieved when the World Health Organization (WHO) reported that, between 2000 and 2015, malaria incidence rates and mortality rates fell significantly in "Africa, Southeast Asia (SEA) regions, Western Pacific region, Eastern Mediterranean region," and other regions in the world [8]. Vector control through insecticide-treated mosquito nets (ITNs) and indoor residual spraying (IRS) has contributed to the control and eradication of malaria in different world regions particularly in Africa [9-12]. Furthermore, the discovery of the effective drug artemisinin has greatly changed the therapeutic approach of malaria and enhanced control and eradication of malaria [13-15]. Artemisinin is isolated from the plant Artemisia annua employed in Chinese traditional medicine [16]. Actually, the Chinese scientist Tu Youyou, who discovered the drug artemisinin, was awarded Nobel Prize in Medicine in 2015 [17, 18]. Emergence of antimalarial drug resistance (AMDR), particularly for the core compound, artemisinin, is a new challenge for future plans to control malaria. In this regard, AMDR is defined as survival and multiplication of malaria parasite under conditions that 
normally stop and cure malaria infection [19]. One of the main advances in AMDR is the identification of mutations responsible for drug resistance [20-22]. Monitoring of AMDR is highly needed in order to adopt different control and therapeutic policies for malaria. Assessing research productivity on malaria in general and those pertaining to drug resistance in particular is extremely important. Such studies are carried out using bibliometric indicators that help identify research trends, hot research topics, international collaboration, and country contribution to the field. In fact several studies have been carried out using bibliometric indicators to assess malaria research in different parts of the world [23-29]. However, none was carried out on AMDR. Therefore, the aim of this study was to give a bibliometric overview of publications on AMDR. The focus of this study will be on documents published in the last decade (2006 to 2015) to give an insight into the most recent research activity in this field and future prospects in order to help health policy makers make future plans on malaria control more relevant.

\section{Methods}

The method and indicators used in this study have been explained in detail in previously published bibliometric studies [30-38]. However, we will present and discuss the approach used in this study as an additional piece of information for readers and other investigators. Scopus, run by Elsevier, is one of the largest electronic databases available for literature retrieval. It is friendly to use and provides functions like "limit" and "exclude" that facilitates data refining and analysis. Furthermore, Scopus has the ability to provide researchers with citation analysis, country profile, institution profile, author profile, and source journals for any set of data in any particular field. Other databases can be used for data analysis and retrieval; however, Scopus remains superior to these databases in terms of volume of literature it has [39].

In this study, the keywords used in Scopus for retrieval of data were as follows: (TITLE("Plasmodium falciparum" OR "PLASMODIUM vivax" OR "Plasmodium malariae" OR "Plasmodium ovale" OR malaria OR "P. vivax" OR "P. falciparum" OR "P. malriae" OR "P. ovale") AND TITLE(“* aminoquinoline resist*” OR “* chloroquine resist" $\mathrm{OR}$ "amodiaquine resist*" OR "pyrimethamine resist" " OR "mefloquine resist*” OR "artemisinin resist" OR “piperaquine resist"” OR "resist" malaria” OR "antimalarial drug resist"”) OR TITLE("proguanil resist"” OR "sulf* resist" " OR "Atovaquone resist" OR "Primaquine resist" " OR "Halofantrine resist*” OR pfcrt* OR pfmdr* OR pfatp * OR pfnhe ${ }^{*}$ OR "dhfr* mutation" OR "dhps* mutation" OR pfmrp OR pfdhfr OR pfdhps) OR TITLE(pfmrp* OR pfcytb* OR "Chloroguanide resist*" OR "quinine resist" OR "Pyronaridine resist*" OR "dihydroartem* resist" OR “arte* resist*” OR "drug resist* malaria” OR "resist" OR pvcrt* OR pvmdr* ${ }^{*}$ AND TITLE(resist*) AND NOT TITLE(insect* OR anopheles OR tuberculosis OR pyrethroid OR mosquito OR avian OR toxoplasma OR cytochrome OR salmonella OR fluoroquinolone OR antifungal OR snake OR organophosphate)) AND PUBYEAR > 2005 AND
TABLE 1: Types of retrieved documents on AMDR (2006-2015).

\begin{tabular}{lcc}
\hline Type of document & Frequency & $\%$ \\
\hline Article & 790 & 80.94 \\
Review & 92 & 9.43 \\
Letter & 31 & 3.18 \\
Note & 24 & 2.46 \\
Short survey & 18 & 1.84 \\
Editorial & 9 & 0.92 \\
Conference paper & 6 & 0.61 \\
Article in press & 6 & 0.61 \\
\hline
\end{tabular}

AMDR: antimalarial drug resistance.

PUBYEAR < 2016 AND (LIMIT-TO(SRCTYPE, “j”)) AND (EXCLUDE(DOCTYPE, “er”)).

These keywords used in this study were chosen based on literature review pertaining to AMDR from all aspects including molecular biology and genetics. To maximize accuracy, all keywords were entered in title search and quotation marks were used wherever appropriate. The time limit of the study was from 2006 to 2015. For the purpose of this study, only journal articles were included in the analysis. Quantitative assessment of AMDR literature was simply carried out by analysis of volume of retrieved articles while scientific impact of the publication was presented as number of citations per article and number of highly cited articles as well as the impact factor (IF) of journals publishing the retrieved articles. The validity of our search query was tested and confirmed by manually reviewing $10 \%$ of top cited articles in the retrieved data. The manual review was carried by the authors themselves. Country affiliation analysis in Scopus can give researchers insight into intra- and intercountry collaboration. Single country publications (SCP) are those that represent intracountry collaboration while multiple country publications (MCP) are those that represent intercountry collaboration. We considered only the top ten ranking countries, institutions, and journals. To visualize country collaboration or coauthorships, VOSviewer was used [40]. VOSviewer can represent information as either density visualizations maps or network visualizations maps. In this study, we used density visualization map as cluster density maps. Each cluster represents group of most frequently and closely collaborating countries where countries having higher numbers of coauthorships are the ones with higher extent of collaboration.

\section{Results}

A total of 976 journal documents were retrieved. Types of retrieved documents are listed in Table 1 . Original research articles $(790 ; 80.94 \%)$ were the main type. A total of 12 different languages were encountered in the retrieved documents. English language (942; 96.52\%) was most commonly encountered followed by French $(16 ; 1.64 \%)$ and Chinese $(6$; $0.30 \%$ ) languages. A total of 125 countries contributed to the publication of retrieved documents. 


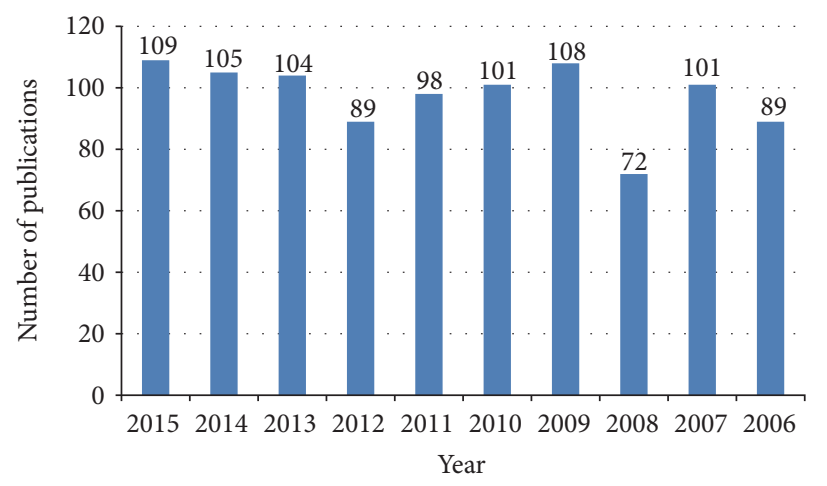

FIgURE 1: Growth of publications on AMDR (2006-2015).

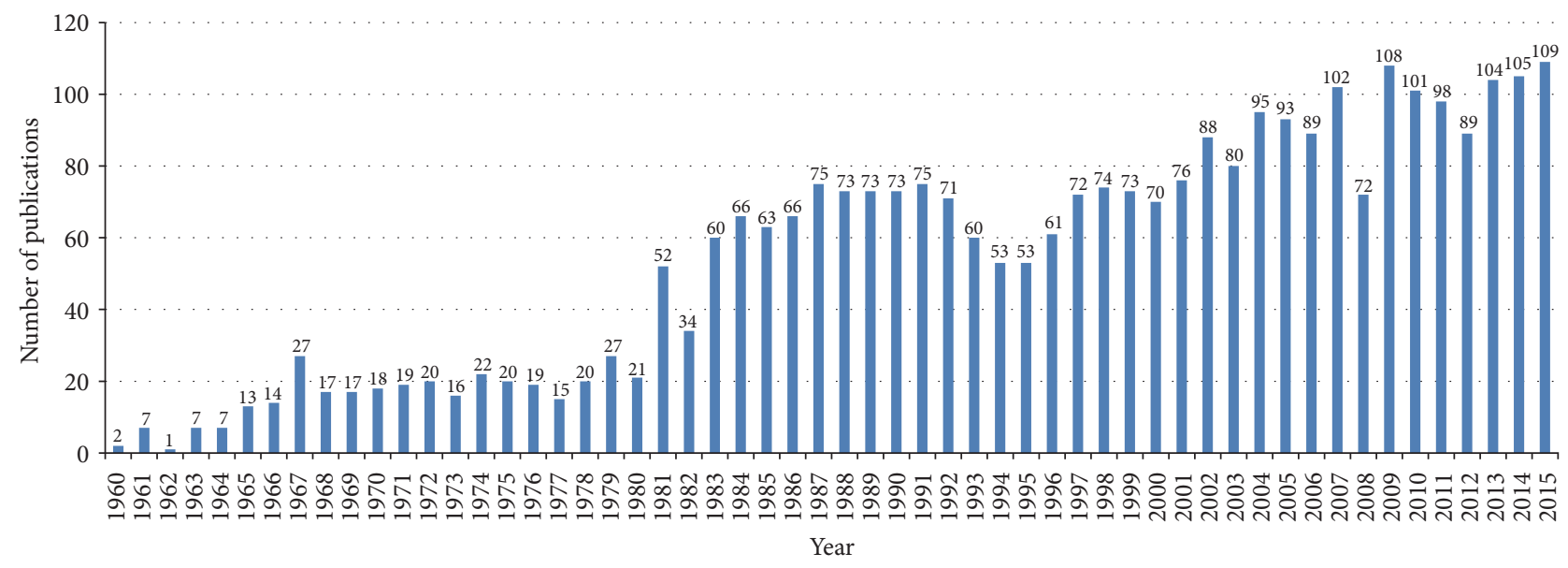

FIgURE 2: Growth of publications on AMDR (1960-2015).

TABLE 2: Growth of annual publications and citations on AMDR (2006-2015).

\begin{tabular}{cccccc}
\hline Year & Total number $=976$ & $\%$ & TC & C/A & CT \\
\hline 2015 & 109 & 11.17 & 608 & 5.58 & 21399 \\
2014 & 105 & 10.76 & 1113 & 10.60 & 20791 \\
2013 & 104 & 10.66 & 1032 & 9.92 & 19678 \\
2012 & 89 & 9.12 & 1834 & 20.61 & 18646 \\
2011 & 98 & 10.04 & 1847 & 18.85 & 16812 \\
2010 & 101 & 10.35 & 1892 & 18.73 & 14965 \\
2009 & 108 & 11.07 & 4635 & 42.92 & 13073 \\
2008 & 72 & 7.38 & 2626 & 36.47 & 8438 \\
2007 & 101 & 10.35 & 3100 & 30.69 & 5812 \\
2006 & 89 & 9.12 & 2712 & 30.47 & 2712 \\
\hline
\end{tabular}

AMDR: antimalarial drug resistance; TC: total citations; C/A: citations per article; h-index: Hirsh index; CT: cumulative citations.

The growth of publications on AMDR showed a fluctuating pattern in the last decade (Figure 1). However, growth of publications showed a noticeable increase when data on AMDR was presented for the last five decades (Figure 2). The average number of publications was approximately 98 documents per year. Table 2 shows the number of publications, total citations, and average number of citations per article in each year for the last decade. The total number of citations of the retrieved documents was 21399 with an h-index of 63. VOSviewer technique was used to find out the most commonly encountered terms in title/abstract of retrieved documents after setting the minimum threshold at 10 . The density visualization map yielded a total of 350 relevant terms distributed in three clusters shown in three different colors (Figure 3). Cluster number one (red) focuses on terms mainly related to chloroquine resistance $(\mathrm{CQR})$ and the genetic basis behind CQR. The second cluster (green) focuses on antifolate drug resistance and the genetic basis of this resistance. The third cluster (blue) focuses on artemisinin related resistance and its geographical distribution in Asia and Africa. Table 3 lists the most frequent terms in each cluster and the number of occurrences of each term.

Geographical distribution of retrieved publications was presented in world map using ArcMap 10.1 program (Figure 4). Top countries that participated in publishing documents on AMDR were listed in Table 4. The United States of America (USA) was the most productive country with 337 publications equivalent to one-third of worldwide publications in this field. The USA and the United Kingdom (UK) participated in more than half $(55.23 \%)$ of worldwide productivity. More than two-thirds of publications by the USA 


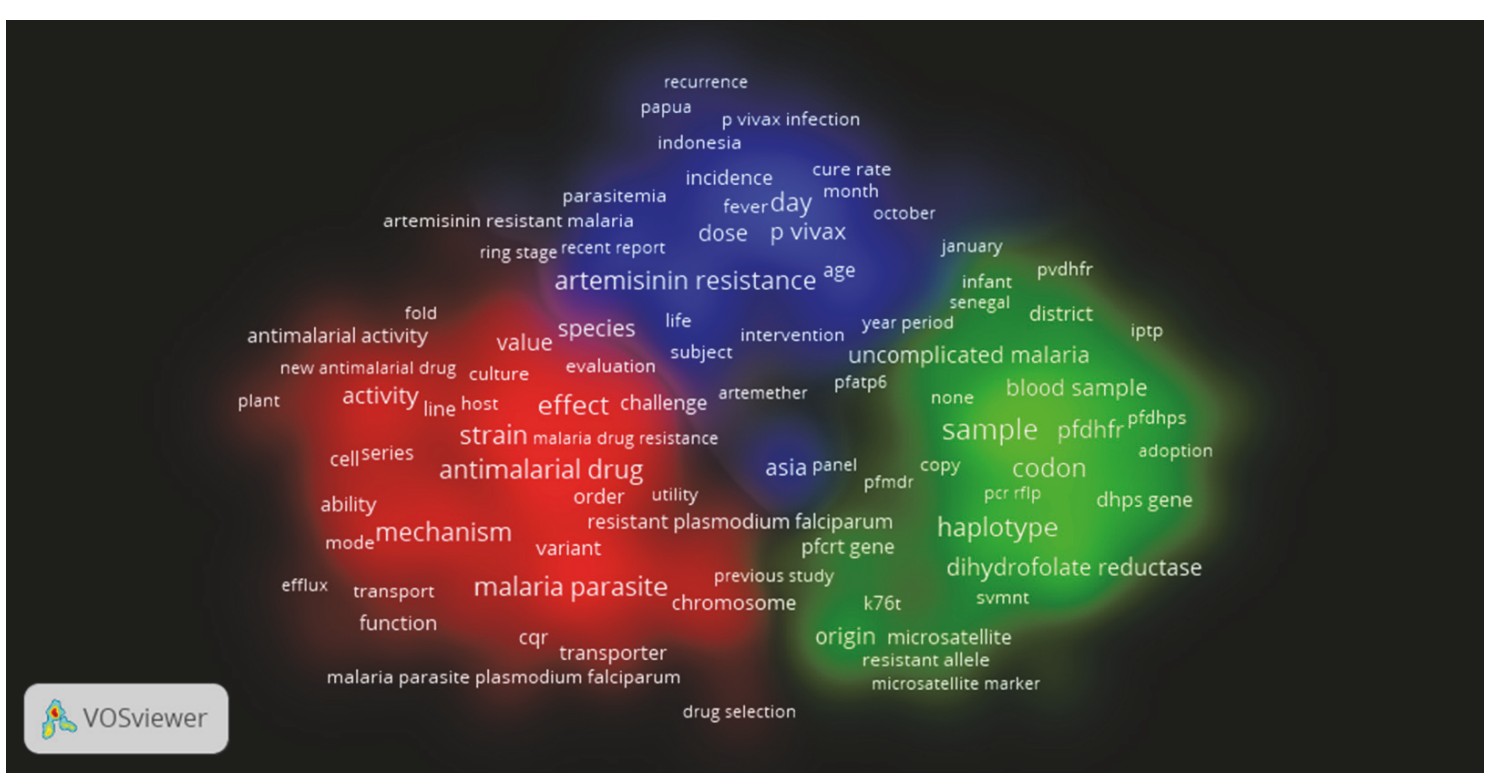

FIGURE 3: Cluster density visualization map of frequently encountered terms in title/abstract of retrieved documents on AMDR (2006-2015). A minimum of 10 yielded 350 terms.

TABLE 3: Most frequent terms in title/abstract of publications on AMDR (2006-2015) using VOSviewer technique.

Terms related to drug resistance, gene mutations, or countries Number of occurrences

Cluster \# 1 (red) = 138 items

Chloroquine resistance transporter 20

Chloroquine-resistant

Chloroquine-resistant malaria

Chloroquine-resistant $P$. falciparum

Chloroquine-resistant parasites

Chloroquine-resistant Plasmodium falciparum 26

Chloroquine-resistant strain 20

CQR (chloroquine resistance) 38

pfcrt mutation 15

Transporter 38

Protein 92

Phenotype

Cluster \# 2 (green) = 123 items

Antifolate drug resistance $\quad 25$

dhfr gene 18

dhps gene 33

dhps mutation 18

pfdhps gene 20

Pyrimethamine resistance $\quad 38$

pfcrt gene

pfmdrl gene

Cluster \# 3 (blue) $=89$ items

Artemisinin resistance 90

Artemisinin-resistant malaria $\quad 17$

Sub-Saharan Africa 23

Thai-Myanmar border 10

$\begin{array}{ll}\text { Papua } & 15\end{array}$

Asia

AMDR: antimalarial drug resistance. 


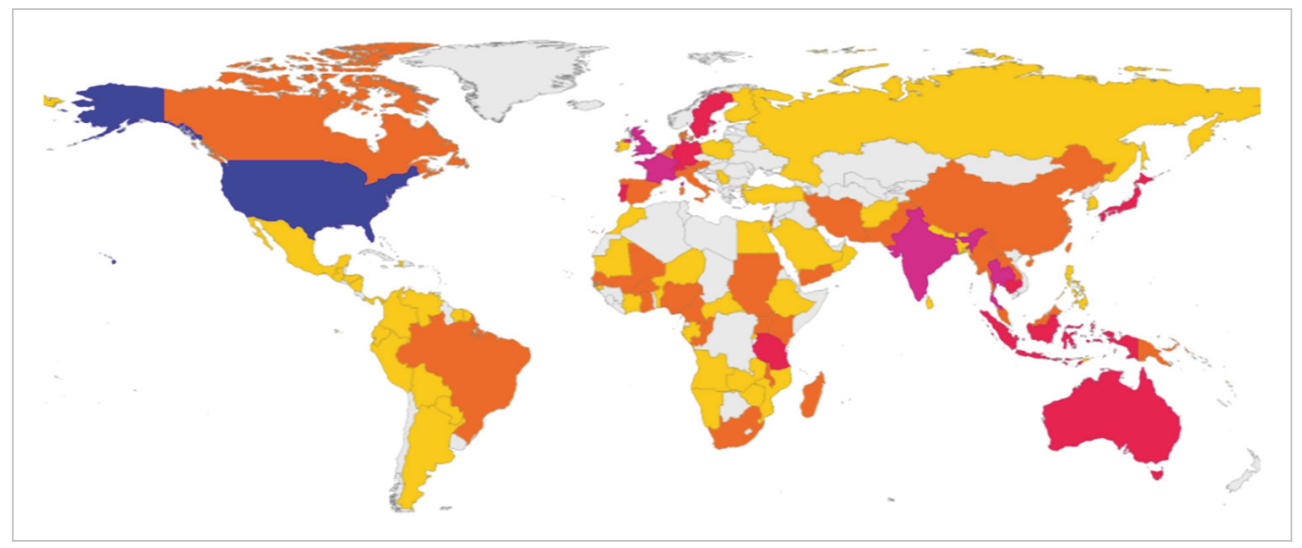

Number of publications

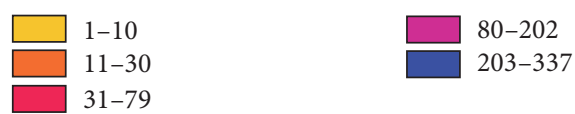

FIGURE 4: Geographical distribution of retrieved articles in antimalarial drug resistance (2006-2015). Gray regions represent countries where no publications regarding antimalarial drug resistance have been retrieved.

TABLE 4: Top ten productive countries, scientific impact, and international collaboration on AMDR (2006-2015).

\begin{tabular}{|c|c|c|c|c|c|c|c|c|}
\hline Rank & Country & $\begin{array}{c}\text { Frequency } \\
N=976\end{array}$ & $\mathrm{TC}$ & $\mathrm{C} / \mathrm{A}$ & h-index & $\mathrm{CC}$ & SCP & $\mathrm{MCP}$ \\
\hline 1 st & United States & $337(34.53)$ & 9498 & 28.18 & 50 & 73 & $101(29.97)$ & $236(70.03)$ \\
\hline 2nd & United Kingdom & $202(20.70)$ & 8702 & 43.08 & 48 & 69 & $15(7.43)$ & $187(92.57)$ \\
\hline $3 \mathrm{rd}$ & Thailand & $129(13.22)$ & 6736 & 52.22 & 39 & 51 & $30(23.26)$ & $99(76.74)$ \\
\hline 4th & France & $90(9.22)$ & 2463 & 27.37 & 28 & 61 & $19(21.11)$ & $71(78.89)$ \\
\hline 5 th & India & 89 (9.12) & 1280 & 14.38 & 18 & 30 & $65(73.03)$ & $24(26.97)$ \\
\hline 6th & Australia & $79(8.09)$ & 3054 & 38.66 & 28 & 45 & $10(12.66)$ & $69(87.34)$ \\
\hline 7 th & Cambodia & $49(5.02)$ & 4645 & 94.80 & 27 & 45 & $0(0.00)$ & $49(100.00)$ \\
\hline 7 th & Switzerland & $49(5.02)$ & 3143 & 64.14 & 22 & 45 & $0(0.00)$ & $49(100.00)$ \\
\hline 9th & Germany & $46(4.71)$ & 1255 & 27.28 & 25 & 54 & $8(17.39)$ & $41(89.13)$ \\
\hline 10th & Portugal & $42(4.30)$ & 970 & 23.10 & 16 & 29 & $3(7.14)$ & $39(92.86)$ \\
\hline
\end{tabular}

AMDR: antimalarial drug resistance; N: total number of publications; TC: total citations; h-index: Hirsch index; CC: cumulative citations; SCP: single country publications; MCP: multiple country publications.

(236, 70.03\%) were made by international collaboration with researchers from other countries. All articles published by Cambodian researchers had international authors representing 100\% international collaboration (MCP). Furthermore, articles published by Cambodian researchers had the highest number of citations per article when compared with articles published by other countries. Of the top productive countries, two countries were from Mekong subregion, particularly Thailand and Cambodia. Analysis of country coauthorships using VOSviewer showed a map with four clusters (Figure 5, Table 5). Countries in the same cluster have higher collaboration than those distantly located in other clusters. Furthermore, countries with higher number of coauthorships had higher number of articles published on international collaboration.

Top journals in publishing documents about AMDR were listed in Table 6. The Malaria Journal was the most productive journal $(136,13.93 \%)$ in this field followed by Antimicrobial Agents and Chemotherapy journal and American Journal of Tropical Medicine and Hygiene. The Proceedings of the National Academy of Sciences (PNAS) had the highest impact factor (9.423) and the highest number of citations per article (49.06). Journal of Infectious Diseases (70.00\%) had the highest percentage of highly cited articles followed by PNAS (62.50\%). The total number of articles published in the top 10 publishing journals was 450 (46.11\%) and the total impact of these articles was 1,704 with an average of 3.79 per article.

Top productive institutions on AMDR were shown in Table 7. The top productive institution was Mahidol University $(80,8.20 \%)$ in Thailand. Another institution in the top-ten list was Shoklo Malaria Research Unit in Thailand which was in the 8 th position. Three of the top ten institutions active in AMDR research were in Asia, particularly in India 
VOSviewer

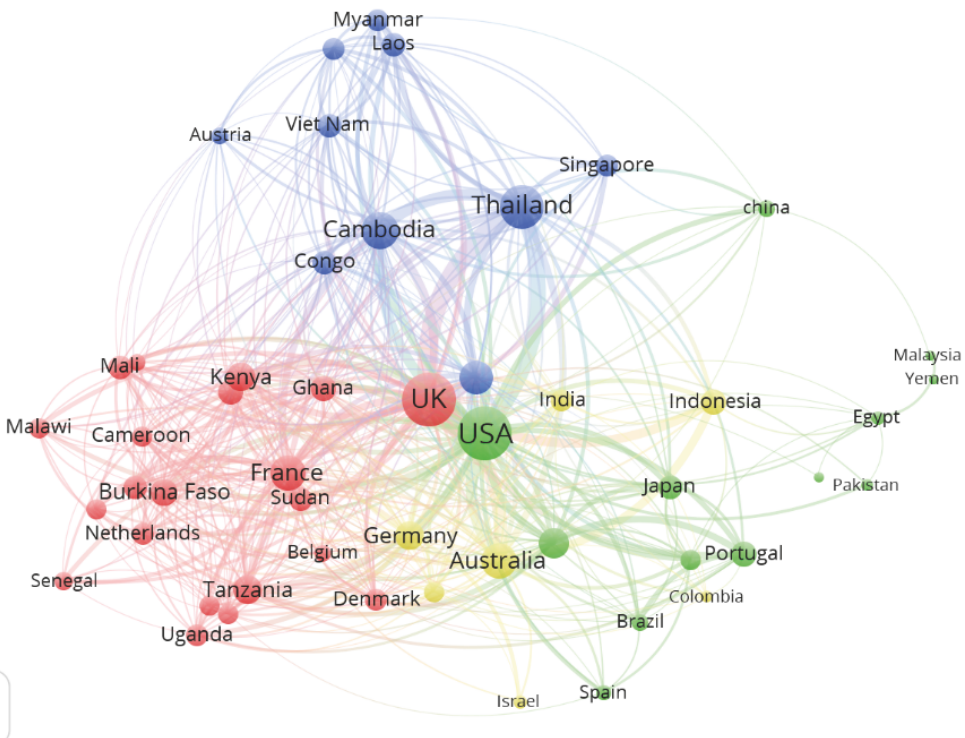

FIGURE 5: Cluster density visualization map of country coauthorships on AMDR (2006-2015). A minimum of 10 gave a total of 51 items and 4 clusters.

TABle 5: Country coauthorship as retrieved by VOSviewer. A minimum of 10 gave a total of 51 items and 4 clusters.

\begin{tabular}{ll}
\hline Cluster number & Items (number of country coauthorships) \\
\hline Cluster \# 1 (red) & Belgium (31), Burkina Faso (94), Cameroon (53), Denmark (61), Ethiopia (47), France (182), Gambia (67), \\
21 items & Ghana (79), Italy (29), Kenya (112), Madagascar (45), Malawi (47), Mali (76), Netherlands (58), Nigeria (80), \\
& Senegal (42), South Africa (47), Sudan (69), Tanzania (121), Uganda (63), United Kingdom (518). \\
Cluster \# 2 (green) & Brazil (35), China (33), Egypt (17), Iran (8), Japan (66), Malaysia (10), Pakistan (13), Papua New Guinea (53), \\
13 items & Portugal (77), Spain (27), Sweden (125), USA (529), Yemen (10). \\
Cluster \# 3 (blue) & Austria (32), Bangladesh (60), Cambodia (203), Congo (70), Laos (76), Myanmar (56), Singapore (56), \\
10 items & Switzerland (158), Thailand (312), Vietnam (69). \\
Cluster \# 4 & \\
(yellowish green) & Australia (197), Canada (47), Colombia (15), Germany (109), India (62), Indonesia (86), Israel (16). \\
7 items &
\end{tabular}

TABLE 6: Top ten journals in publishing articles on AMDR (2006-2015).

\begin{tabular}{|c|c|c|c|c|c|c|c|c|}
\hline Rank & Journal & $\begin{array}{c}\text { Frequency } \\
(\%) \\
N=976\end{array}$ & $\mathrm{TC}$ & h-index & $\mathrm{C} / \mathrm{A}$ & $\mathrm{HC}(\%)$ & IF & Total IF \\
\hline 1 st & Malaria Journal & $136(13.93)$ & 1860 & 22 & 13.68 & $29(21.32)$ & 3.079 & 418.744 \\
\hline 2nd & Antimicrobial Agents and Chemotherapy & $96(9.84)$ & 2017 & 27 & 21.01 & $41(42.71)$ & 3.34 & 320.64 \\
\hline $3 \mathrm{rd}$ & American Journal of Tropical Medicine and Hygiene & $56(5.74)$ & 1124 & 19 & 20.07 & $19(33.93)$ & 2.699 & 151.144 \\
\hline 4 th & Plos One & $38(3.89)$ & 733 & 16 & 19.29 & $13(34.21)$ & 3.54 & 134.52 \\
\hline 5 th & Journal of Infectious Diseases & $30(3.07)$ & 997 & 21 & 33.23 & $21(70.00)$ & 6.344 & 190.32 \\
\hline 6 th & Acta Tropica & $26(2.66)$ & 358 & 12 & 13.77 & $7(26.92)$ & 2.380 & 61.88 \\
\hline 7th & Infection Genetics and Evolution & $21(2.15)$ & 285 & 9 & 13.57 & $5(23.81)$ & 2.591 & 54.411 \\
\hline 8th & PNAS & $16(1.64)$ & 785 & 12 & 49.06 & $10(62.50)$ & 9.423 & 150.768 \\
\hline 8 th & Trends in Parasitology & $16(1.64)$ & 242 & 9 & 15.13 & $4(25.00)$ & 7.295 & 116.72 \\
\hline \multirow[t]{2}{*}{ 10th } & Emerging Infectious Diseases & $15(1.54)$ & 229 & 9 & 15.27 & $3(20.00)$ & 6.99 & 104.85 \\
\hline & Total & $450(46.11 \%)$ & & & & & & 1,704 \\
\hline
\end{tabular}

PNAS: Proceedings of the National Academy of Sciences of the United States of America; AMDR: antimalarial drug resistance; $N$ : total number of publications; TC: total citations; h-index: Hirsch index; C/A: citations per article; IF: impact factor. 
TABLE 7: Top ten productive institutions in publishing articles on AMDR (2006-2015).

\begin{tabular}{|c|c|c|c|c|c|c|c|}
\hline Rank & Institution (affiliation) & Country & Frequency $(\%)$ & TC & $\mathrm{C} / \mathrm{A}$ & h-index & $\mathrm{HC}(\%)$ \\
\hline 1st & Mahidol University & Thailand & $80(8.20)$ & 5197 & 64.96 & 34 & $38(47.50)$ \\
\hline 2nd & London School of Hygiene \& Tropical Medicine & UK & $62(6.35)$ & 2033 & 32.79 & 25 & $21(33.87)$ \\
\hline $3 \mathrm{rd}$ & Oxford University (Nuffield Department of Clinical Medicine) & $\mathrm{UK}$ & $45(4.61)$ & 1471 & 32.69 & 20 & $15(33.33)$ \\
\hline 4 th & National Institute of Allergy and Infectious Diseases & USA & $39(4.00)$ & 2247 & 57.62 & 23 & $21(53.85)$ \\
\hline 5 th & National Institute of Malaria Research India & India & $37(3.79)$ & 2951 & 79.76 & 19 & $15(40.54)$ \\
\hline 6th & Organisation Mondiale de la Sante & WHO & $32(3.28)$ & 2951 & 92.22 & 19 & $15(46.88)$ \\
\hline 7 th & Centers for Disease Control and Prevention & USA & $31(3.18)$ & 877 & 28.29 & 16 & $9(29.03)$ \\
\hline 7 th & Menzies School Of Health Research & Australia & $29(2.97)$ & 1854 & 63.93 & 20 & $16(55.17)$ \\
\hline 9 th & Shoklo Malaria Research Unit & Thailand & $28(2.87)$ & 3016 & 107.71 & 20 & $19(67.86)$ \\
\hline 10th & University of California, San Francisco & USA & $26(2.66)$ & 691 & 26.58 & 15 & $10(38.46)$ \\
\hline
\end{tabular}

TC: total citations; C/A: citations per article; h-index: Hirsch index; HC (\%): percentage of articles with high citations.

TABLE 8: Top cited articles on AMDR (2006-2015).

\begin{tabular}{|c|c|c|c|c|}
\hline Rank & Authors & Title & Source title & Number of citations \\
\hline 1st & Dondorp et al. [41] & $\begin{array}{c}\text { "Artemisinin Resistance in Plasmodium falciparum } \\
\text { Malaria" }\end{array}$ & $\begin{array}{l}\text { New England Journal of } \\
\text { Medicine }\end{array}$ & 1350 \\
\hline 2nd & Noedl et al. [42] & $\begin{array}{c}\text { "Evidence of Artemisinin-Resistant Malaria in Western } \\
\text { Cambodia" }\end{array}$ & $\begin{array}{l}\text { New England Journal of } \\
\text { Medicine }\end{array}$ & 688 \\
\hline $3 \mathrm{rd}$ & Phyo et al. [43] & $\begin{array}{l}\text { "Emergence of Artemisinin-Resistant Malaria on the } \\
\text { Western Border of Thailand: A Longitudinal Study" }\end{array}$ & The Lancet & 354 \\
\hline 4 th & Ariey et al. [44] & $\begin{array}{c}\text { "A molecular Marker of Artemisinin-Resistant } \\
\text { Plasmodium falciparum Malaria" }\end{array}$ & Nature & 319 \\
\hline 5 th & Tjitra et al. [45] & $\begin{array}{c}\text { "Multidrug-Resistant Plasmodium vivax Associated } \\
\text { with Severe and Fatal Malaria: A Prospective Study in } \\
\text { Papua, Indonesia" }\end{array}$ & PLoS Medicine & 301 \\
\hline 6 th & Ashley et al. [46] & $\begin{array}{l}\text { "Spread of Artemisinin Resistance in Plasmodium } \\
\text { falciparum Malaria" }\end{array}$ & $\begin{array}{l}\text { New England Journal of } \\
\text { Medicine }\end{array}$ & 263 \\
\hline 7 th & Price et al. [47] & $\begin{array}{l}\text { "New Developments in Plasmodium vivax Malaria: } \\
\text { Severe Disease and the Rise of Chloroquine Resistance" }\end{array}$ & $\begin{array}{l}\text { Current Opinion in } \\
\text { Infectious Diseases }\end{array}$ & 197 \\
\hline 8 th & Cheeseman et al. [48] & $\begin{array}{c}\text { "A Major Genome Region Underlying Artemisinin } \\
\text { Resistance in Malaria" }\end{array}$ & Science & 172 \\
\hline 9th & Ter Kuile et al. [49] & $\begin{array}{c}\text { "Effect of Sulfadoxine-Pyrimethamine Resistance on } \\
\text { the Efficacy of Intermittent Preventive Therapy for } \\
\text { Malaria Control during Pregnancy: A Systematic } \\
\text { Review" }\end{array}$ & $\begin{array}{l}\text { Journal of the American } \\
\text { Medical Association }\end{array}$ & 170 \\
\hline 10th & Price et al. [50] & $\begin{array}{l}\text { "Molecular and Pharmacological Determinants of the } \\
\text { Therapeutic Response to Artemether-Lumefantrine in } \\
\text { Multidrug-Resistant Plasmodium falciparum Malaria" }\end{array}$ & Clinical Infectious Diseases & 161 \\
\hline
\end{tabular}

and Thailand. Both World Health Organization (WHO) and Centers for Disease Prevention and Control (CDC) were among the top ten productive institutions. Citations per article were the highest for documents published from Shoklo Malaria Research Center (107.71) followed by those published by WHO (92.22). For all research institutions/organizations in top-ten list, artemisinin resistance and biomarkers for artemisinin resistance were their major research focus.

Top ten cited articles on AMDR published in the past decade were presented in Table 8. The article "Artemisinin Resistance in Plasmodium falciparum Malaria" which received a total of 1350 citations at the time of data analysis
(July 15, 2016) was the top cited article. Three articles in the top ten cited list were published in New England Journal of Medicine. Two of the top ten cited articles were published in Science and Nature, and one article was published in The Lancet. Seven articles in the top-ten list were about artemisinins resistance in Plasmodium falciparum, one was about CQR, one was about sulfadoxine-pyrimethamine resistance, and the remaining one was about general multidrug resistance.

Authors participating in publications of AMDR with at least 10 documents were shown in the VOSviewer visualization map (Figure 6). Table 9 lists authors with a minimum 


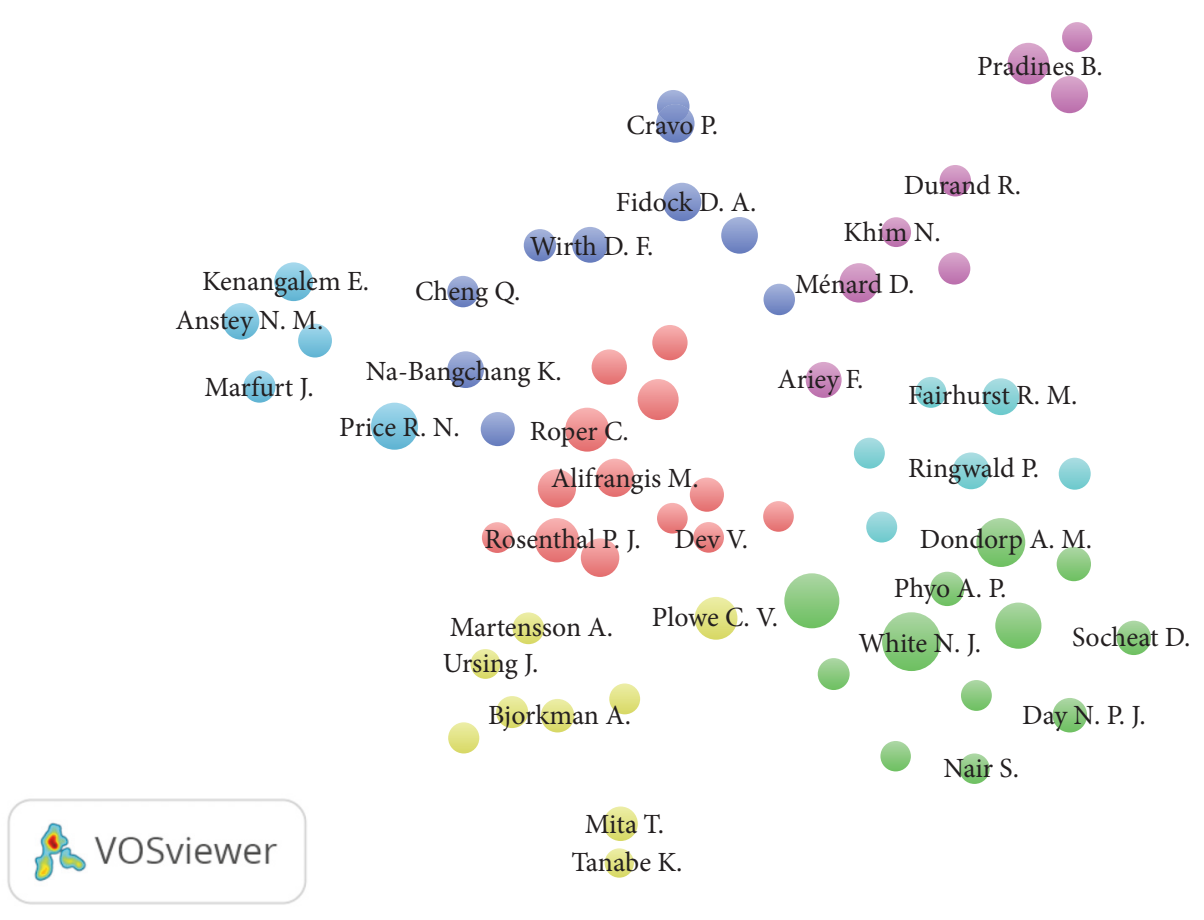

FIGURE 6: Density visualization map for researchers' coauthorships on AMDR (2006-2015). A minimum of 10 yielded 63 authors.

TABLE 9: List of authors, number of coauthorships, and location in cluster as retrieved from VOSviewer. Researchers with a minimum of 15 documents on AMDR (2006-2015) were shown.

\begin{tabular}{|c|c|c|c|}
\hline Author & Number of publications & Number of coauthorships & Cluster \\
\hline Nosten, F. & 35 & 148 & 2 \\
\hline White, N. J. & 28 & 186 & 2 \\
\hline Imwong, M. & 25 & 131 & 2 \\
\hline Price, R. N. & 25 & 88 & 7 \\
\hline Roper, C. & 23 & 15 & 1 \\
\hline Plowe, C. V. & 21 & 74 & 4 \\
\hline Pradines, $\mathrm{B}$. & 21 & 28 & 5 \\
\hline Dondorp, A. M. & 20 & 149 & 2 \\
\hline Rosenthal, P. J. & 20 & 22 & 1 \\
\hline Udhayakumar, V. & 19 & 31 & 1 \\
\hline Alifrangis, $\mathrm{M}$. & 17 & 8 & 1 \\
\hline Kenangalem, E. & 17 & 55 & 7 \\
\hline Rogier, C. & 17 & 27 & 5 \\
\hline Meshnick, S. R. & 16 & 35 & 1 \\
\hline Ménard, D. & 24 & 41 & 5 \\
\hline Sutherland, C. J. & 16 & 22 & 1 \\
\hline Anstey, N. M. & 15 & 51 & 7 \\
\hline Fairhurst, R. M. & 15 & 81 & 6 \\
\hline Fidock, D. A. & 15 & 14 & 3 \\
\hline Na-Bangchang, K. & 15 & 3 & 3 \\
\hline Ringwald, P. & 15 & 70 & 6 \\
\hline Roepe, P. D. & 15 & 5 & 3 \\
\hline Wirth, D. F. & 15 & 6 & 3 \\
\hline
\end{tabular}


of 15 publications and their location in the map. The map contained seven clusters. The most productive authors were clustered together in cluster numbers 1 and 2 mainly.

\section{Discussion}

In this study we aimed to give an overview and an assessment of an emerging important issue regarding antimalarial drug resistance which threatens global efforts to control and eradicate malaria. Although bark of cinchona tree and other related synthetic compounds had been used to treat malaria for centuries, the emergence of resistance to antimalarial drugs is considered relatively recent medical phenomenon. It has been reported that early cases of chloroquine-resistant form of $P$. falciparum appeared in Thailand in the late 1950s. In the 1960 s more cases of resistant $P$. falciparum were seen in Southeast Asia followed by the appearance of resistant cases in Sub-Saharan Africa and South America in the 1970s. The spread of chloroquine resistance in the 1970s and 1980s led researcher to develop and introduce new antimalarial drugs to combat the increasing numbers of malaria induced mortality due to antimalarial drug resistance in P. falciparum [51-53]. Sulfadoxine-pyrimethamine, an alternative to chloroquine, faced drug-resistant Plasmodium species soon after introduction [54]. Unfortunately, most new attempts such as introduction of mefloquine, amodiaquine, and artemisinin faced the same problem of drug resistance with time. The fight against malaria recorded a success upon introduction of insecticide-treated bed nets and indoor residual insecticide spraying [55]. The origin and the emergence of resistance to antimalarial drugs has been developed mainly through genetic mutations which involved chloroquine resistance transporter (PfCRT), Plasmodium falciparum multidrug resistance gene-1 (PfMDR), dihydrofolate reductase (DHFR), dihydropteroate synthase (DHPS), and several others [56]. The genetic mutation that led to chloroquine resistance developed independently in Papua New Guinea, certain locations in South America, and Asia which then spread through Southeast Asia and Africa [57-59]. It is believed that spread of resistance to chloroquine did not emerge within infected individuals; rather, it was a spread of emerging mutations due to drug pressure [56]. This hypothesis was tested by removal of drug pressure which led to a decrease in the prevalence of the PfCRT $76 \mathrm{~T}$ mutation associated with chloroquine resistance [60]. Resistance in $P$. falciparum is complicated by increasing resistance to artemisinin partner drugs such as piperaquine. Molecular markers for drug resistance are currently used for monitoring expected therapeutic outcomes and for directing policy changes towards suitable combination therapies. Markers are available for artemisinin resistance, mefloquine resistance, and recently piperaquine resistance (plasmepsin 2 and plasmepsin 3 gene amplifications on chromosome 14) [44, 61-63].

Our study showed that the number of publications on AMDR was fluctuating in the last decade. However, when the number of publications on AMDR was presented for the past five decades, it was apparent that there was an overall increase in the number of publications in the past decade.
It was expected that publications on AMDR will decrease with time especially after the introduction of artemisinins as new potent and effective therapy for malaria. However, the emergence of resistance to artemisinins kept the number of publications on AMDR rising with time [64-68]. This new wave of AMDR is accompanied by global concern regarding attaining goals of malaria control in Africa, Asia, and other regions.

The Global Technical Strategy for Malaria 2016-2030 aimed at reducing incidence, mortality, and resurgence of malaria in endemic countries. This ambitious goal is costly but will save lives and have a cost-effective long term outcome. The emergence of AMDR in general and those pertaining to artemisinin in particular threatens the Global Technical Strategy for Malaria 2016-2030. Unfortunately, AMDR reports in the past decade originated from areas suffering from poor health services and depending on international health aids to combat malaria such as some African countries or countries in the Mekong region [69]. The emergence of AMDR is considered a recent phenomenon relative to the long history and extensive use of antimalarials in different parts of the world. Such AMDR were reported in the late 1950s and showed a marked increase and spread in 1970, particularly for those pertaining to chloroquine. This emergence of AMDR was associated with increased malaria rate of death and increased calls by health policy makers and international health organization to discover new antimalarial drugs that are not prone to resistance $[51,70]$. In response to this serious threat of AMDR, the International Centers of Excellence for Malaria Research (ICEMRs) had developed an ICEMR network to monitor AMDR at global level [20].

The global concern on AMDR is manifested in the high $\mathrm{h}$-index value suggesting that there are many readers and citations on the topic. Another indicator for the global concern on AMDR is the top cited articles on AMDR which focused on artemisinin drug resistance in some poor and developing areas like Thailand, Cambodia, and Indonesia. Countries in SEA might be the source of artemisinin drug resistance outbreaks and consequent spread of this resistant to other world regions [71]. The genetic basis of artemisinin drug resistance was common in most areas being investigated in greater Mekong area and is associated with PfKelch gene on chromosome 13 (K13) [72]. The potential spread of artemisinin resistance to African countries and other world regions is considered a priority for many international health bodies like WHO. The strategic plan suggested by WHO to prevent the spread or emergence of new geographic spots of artemisinin resistance does not seem to be successful [73]. Understanding the genetic and genomic investigation and the elucidation of molecular markers to AMDR will, hopefully, help in designing new antimalarial drugs. For example, several new compounds are being tested after discovery and understanding of the role of pfcrt in drug resistance [74].

The density visualization maps shed lights on areas of interest on the field of AMDR. The genetic and molecular understanding of AMDR of chloroquine and DHFR inhibitors occupied a central part in the publications on AMDR in the last decade. However. The emerging 
artemisinins drug resistance also occupied a single large cluster of publications. The publications in the last decade were in the field of molecular biology/genetics of AMDR and characterization of artemisinins drug resistance. These important topics were important in ranking top productive countries. Therefore, developed countries in which molecular and genetic advancement and research are active occupied top ranking positions. Such countries include the USA and the UK. However, countries like Thailand, Cambodia, and India where mainly involved in research pertaining to epidemiology and characterization of the emerging artemisinins drug resistance in Asia region, particularly the Mekong region where malaria is endemic. Publications from Thailand and Cambodia were characterized by high citations per article suggestive of relatively high importance in the field. It seems that all or nearly most of the publications from Thailand and Cambodia came through international research collaboration since this topic is of a global concern and research collaboration in this field is highly needed. Also, the limited resources and expertise of countries in the SER relative to those in Europe and northern American countries made international collaboration a must in order to understand and overcome this serious threat of AMDR to ultimately control the fatal infectious disease of malaria. The research activity on AMDR in Thailand was carried out mainly by two institutions which are presented in the top ten productive institutions along with prestigious organizations and institutions like WHO and CDC.

The retrieved articles discussed various issues that cannot be listed here in detail. However, it is worth commenting on articles that discussed potential causes of AMDR. The WHO recommends artemisinin-based combination therapies (ACTs) for the treatment of malaria to minimize development of artemisinin drug resistance $[75,76]$. The ACTs are considered first-line treatment of malaria in most countries and hundreds of millions of ACTs treatment courses were dispensed in the past few years in endemic countries [76]. Therefore drug use without appropriate combination is one mechanism responsible for the development of AMDR [77]. Furthermore, unregulated and irrational use of antimalarial drug use as well as counterfeit and poor quality medicines dispensed in Africa and other parts of the world might be responsible for the spread and development of AMDR [7880]. Genetic variations of malaria parasites from one region to another are also a potential cause for the development and resistance of AMDR [51, 81, 82].

This study, to the authors' best knowledge, is the first to discuss the AMDR from a bibliometric analysis point of view. However, few limitations pertaining to the study need to be mentioned which have already been mentioned in previous bibliometric studies published by the authors [83-90]. An important limitation is the keywords used which might not be $100 \%$ comprehensive and therefore false positive and false negative results are possible. Also, data were retrieved from Scopus and, unfortunately, this does not represent $100 \%$ of literature because some journals are not indexed in Scopus. Finally, we analyzed the scientific impact of top ten countries, journals, and institutions and not all data. Despite all this, the authors did their best to validate the data by manual review and tried to give a close overall assessment on ADMR research productivity that hopefully will be a positive addition to the literature on AMDR.

\section{Conclusion}

This study showed an increased interest in the artemisinin drug resistance as well as molecular biology and genetics of AMDR in general. Countries and institutions in the Mekong subregion had a good share of publication on AMDR. International collaboration is of great value and can enhance the quantity and scientific impact of publications on AMDR, particularly in countries with limited resources like the case of some Asian countries. Articles on AMD have been published in prestigious journals with high IF indicative of the global concern and dimension of the AMDR issue.

\section{Abbreviations \\ UNICEF: United Nations Children's Emergency Fund \\ WHO: World Health Organization \\ CDC: Centers for Disease Preventions and Control \\ AMDR: Antimalarial drug resistance.}

\section{Data Access}

All data present in this article can be retrieved from Scopus using keywords listed in the methodology.

\section{Conflicts of Interest}

The authors declare that they have no financial or nonfinancial competing interests.

\section{Authors' Contributions}

Waleed M. Sweileh and Sa'ed H. Zyoud contributed to the idea, concept, and manuscript preparation. Samah W. Al-Jabi, Adham S. AbuTaha, and Ansam F. Sawalha contributed to data extraction, analysis, and presentation.

\section{References}

[1] P. L. Alonso and M. Tanner, "Public health challenges and prospects for malaria control and elimination," Nature Medicine, vol. 19, no. 2, pp. 150-155, 2013.

[2] World Health Organization, Fact Sheet: World Malaria Report 2015, 2015, http://www.who.int/malaria/media/world-malariareport-2015/en/.

[3] C. J. Murray, K. F. Ortblad, C. Guinovart et al. et al., "Global, regional, and national incidence and mortality for HIV, tuberculosis, and malaria during 1990-2013: a systematic analysis for the Global Burden of Disease Study 2013," Lancet, vol. 384, no. 9947, pp. 1005-1070, 2014.

[4] N. J. White, S. Pukrittayakamee, and T. T. Hien, "Malaria," The Lancet, vol. 383, no. 9918, pp. 723-735, 2013.

[5] L. H. Miller, H. C. Ackerman, X.-Z. Su, and T. E. Wellems, "Malaria biology and disease pathogenesis: insights for new treatments," Nature Medicine, vol. 19, no. 2, pp. 156-167, 2013. 
[6] P. Dasari and S. Bhakdi, "Pathogenesis of malaria revisited," Medical Microbiology and Immunology, vol. 201, no. 4, pp. 599604, 2012.

[7] United Nations (UN), Millennium Development Goals and Beyond, 2015, http://www.un.org/millenniumgoals/aids.shtml.

[8] N. J. White, "Declining malaria transmission and pregnancy outcomes in southern Mozambique," New England Journal of Medicine, vol. 373, no. 17, pp. 1670-1671, 2015.

[9] A. della Torre, B. Arca, G. Favia, V. Petrarca, and M. Coluzzi, "The role of research in molecular entomology in the fight against malaria vectors., Parassitologia, vol. 50, no. 1-2, pp. 137140,2008 .

[10] J. Hemingway, "The role of vector control in stopping the transmission of malaria: threats and opportunities," Philosophical transactions of the Royal Society of London. Series B, Biological sciences, vol. 369, no. 1645, p. 20130431, 2014.

[11] S. Lal, C. Lahariya, and V. K. Saxena, "Insecticide treated nets, antimalarials and child survival in India," Indian Journal of Pediatrics, vol. 77, no. 4, pp. 425-430, 2010.

[12] G. D. Zhu, J. Cao, H. Y. Zhou, and Q. Gao, "[Research progress on malaria vector control]," Zhongguo Xue Xi Chong Bing Fang Zhi Za Zhi, vol. 25, no. 3, pp. 312-315, 2013.

[13] E. Hempelmann, I. Tesarowicz, and B. J. Oleksyn, "Concise history of malaria chemotherapy: From onions to artemisinin," Pharmazie in Unserer Zeit, vol. 38, no. 6, pp. 500-507, 2009.

[14] N. J. White, "Assessment of the pharmacodynamic properties of antimalarial drugs in vivo," Antimicrobial Agents and Chemotherapy, vol. 41, no. 7, pp. 1413-1422, 1997.

[15] G. Brown, "Artemisinin and a new generation of antimalarial drugs," Education in Chemistry, vol. 43, no. 4, pp. 97-99, 2006.

[16] Z. Guo, "Artemisinin anti-malarial drugs in China," Acta Pharmaceutica Sinica B, vol. 6, no. 2, pp. 115-124, 2016.

[17] E. Callaway and D. Cyranoski, "Anti-parasite drugs sweep Nobel prize in medicine 2015," Nature, vol. 526, no. 7572, pp. 174-175, 2015.

[18] D. L. Klayman, "Qinghaosu (Artemisinin): An antimalarial drug from China," Science, vol. 228, no. 4703, pp. 1049-1055, 1985.

[19] C. H. Sibley and R. N. Price, "Monitoring antimalarial drug resistance: applying lessons learned from the past in a fastmoving present," International Journal for Parasitology: Drugs and Drug Resistance, vol. 2, pp. 126-133, 2012.

[20] L. Cui, S. Mharakurwa, D. Ndiaye, P. K. Rathod, and P. J. Rosenthal, "Antimalarial drug resistance: Literature review and activities and findings of the ICEMR network," American Journal of Tropical Medicine and Hygiene, vol. 93, pp. 57-68, 2015.

[21] A. Ecker, A. M. Lehane, J. Clain, and D. A. Fidock, "PfCRT and its role in antimalarial drug resistance," Trends in Parasitology, vol. 28, no. 11, pp. 504-514, 2012.

[22] E. A. Winzeler and M. J. Manary, "Drug resistance genomics of the antimalarial drug artemisinin," Genome Biology, vol. 15, no. 11, article no. 544, 2014.

[23] H. Fu, T. Hu, J. Wang et al., "A bibliometric analysis of malaria research in China during 2004-2014," Malaria Journal, vol. 14, no. 1, article no. 195, 2015.

[24] K. C. Garg, S. Kumar, Y. Madhavi, and M. Bahl, "Bibliometrics of global malaria vaccine research," Health Information and Libraries Journal, vol. 26, no. 1, pp. 22-31, 2009.

[25] B. M. Gupta and A. Bala, "A bibliometric analysis of malaria research in India during 1998-2009," Journal of Vector Borne Diseases, vol. 48, no. 3, pp. 163-170, 2011.
[26] G. Lewison, S. Lipworth, and A. De Francisco, "Input indicators from output measures: A bibliometric approach to the estimation of malaria research funding," Research Evaluation, vol. 11, no. 3, pp. 155-163, 2002.

[27] R. K. Maharana, "Malaria research in India during 2003-2012: A bibliometric analysis," Collection Building, vol. 33, no. 2, pp. 53-59, 2014.

[28] M. Munoz-Urbano, A. F. Lopez-Isaza, N. Hurtado-Hurtado et al., "Scientific research in malaria: bibliometric assessment of the Latin-American contributions," Recent patents on antiinfective drug discovery, vol. 9, no. 3, pp. 209-215, 2014.

[29] A. M. Van Eijk, J. Hill, S. Povall, A. Reynolds, H. Wong, and F. O. Ter Kuile, "The Malaria in Pregnancy Library: A bibliometric review," Malaria Journal, vol. 11, article no. 362, 2012.

[30] S. H. Zyoud, S. W. Al-Jabi, W. M. Sweileh, and R. Awang, "A bibliometric analysis of toxicology research productivity in Middle Eastern Arab countries during a 10-year period (20032012)," Health Research Policy and Systems, vol. 12, no. 1, article no. $4,2014$.

[31] S. H. Zyoud, S. W. Al-Jabi, and W. M. Sweileh, "Worldwide research productivity of paracetamol (acetaminophen) poisoning: A bibliometric analysis (2003-2012)," Human and Experimental Toxicology, vol. 34, no. 1, pp. 12-23, 2015.

[32] S. H. Zyoud, S. W. Al-Jabi, W. M. Sweileh, and R. Awang, "A bibliometric analysis of research productivity of Malaysian publications in leading toxicology journals during a 10 -year period (2003-2012)," Human and Experimental Toxicology, vol. 33, no. 12, pp. 1284-1293, 2014.

[33] S. H. Zyoud, S. W. Al-Jabi, W. M. Sweileh, and W. S. Waring, "Scientific research related to calcium channel blockers poisoning," Human and Experimental Toxicology, vol. 34, no. 11, pp. 1162-1170, 2015.

[34] W. M. Sweileh, S. W. Al-Jabi, A. F. Sawalha, and S. H. Zyoud, "Bibliometric profile of the global scientific research on autism spectrum disorders," SpringerPlus, vol. 5, no. 1, article no. 1480, 2016.

[35] W. M. Sweileh, N. Y. Shraim, S. W. Al-Jabi et al., "Assessing worldwide research activity on probiotics in pediatrics using Scopus database: 1994-2014," World Allergy Organization Journal, vol. 9, no. 1, article no. 25, 2016.

[36] W. M. Sweileh, S. H. Zyoud, S. W. Al-Jabi, A. F. Sawalha, and N. Y. Shraim, "Drinking and recreational water-related diseases: A bibliometric analysis (1980-2015)," Annals of Occupational and Environmental Medicine, vol. 28, no. 1, article no. 40, 2016.

[37] S. H. Zyoud, S. H. Zyoud, S. W. Al-Jabi, W. M. Sweileh, and R. Awang, "Contribution of Arab countries to pharmaceutical wastewater literature: A bibliometric and comparative analysis of research output," Annals of Occupational and Environmental Medicine, vol. 28, no. 1, article no. 28, 2016.

[38] S. H. Zyoud, W. S. Waring, S. W. Al-Jabi, W. M. Sweileh, B. Rahhal, and R. Awang, "Intravenous Lipid Emulsion as an Antidote for the Treatment of Acute Poisoning: A Bibliometric Analysis of Human and Animal Studies," Basic and Clinical Pharmacology and Toxicology, vol. 119, no. 5, pp. 512-519, 2016.

[39] M. E. Falagas, E. I. Pitsouni, G. A. Malietzis, and G. Pappas, "Comparison of PubMed, Scopus, Web of Science, and Google Scholar: Strengths and weaknesses," FASEB Journal, vol. 22, no. 2, pp. 338-342, 2008.

[40] N. J. van Eck and L. Waltman, VOSviewer manual, Leiden: Univeristeit Leiden, 2013, http://www.vosviewer.com/ documentation/Manual_VOSviewer_1.5.4.pdf. 
[41] A. M. Dondorp, F. Nosten, P. Yi et al., "Artemisinin resistance in Plasmodium falciparum malaria," The New England Journal of Medicine, vol. 361, no. 5, pp. 455-467, 2009.

[42] H. Noedl, Y. Se, K. Schaecher, B. L. Smith, D. Socheat, and M. M. Fukuda, "Evidence of artemisinin-resistant malaria in Western Cambodia," The New England Journal of Medicine, vol. 359, pp. 2619-2620, 2008.

[43] A. P. Phyo, S. Nkhoma, K. Stepniewska et al., "Emergence of artemisinin-resistant malaria on the western border of Thailand: a longitudinal study," The Lancet, vol. 379, no. 9830, pp. 1960-1966, 2012.

[44] F. Ariey, B. Witkowski, C. Amaratunga et al., "A molecular marker of artemisinin-resistant Plasmodium falciparum malaria," Nature, vol. 505, no. 7481, pp. 50-55, 2014.

[45] E. Tjitra, N. M. Anstey, P. Sugiarto et al., "Multidrug-resistant Plasmodium vivax associated with severe and fatal malaria: a prospective study in Papua, Indonesia," PLoS Medicine, vol. 5, no. 6, pp. 0890-0899, 2008.

[46] E. A. Ashley, M. Dhorda, R. M. Fairhurst et al. et al., "Spread of artemisinin resistance in Plasmodium falciparum malaria," New England Journal of Medicine, vol. 371, no. 5, pp. 411-423, 2014.

[47] R. N. Price, N. M. Douglas, and N. M. Anstey, "New developments in Plasmodium vivax malaria: severe disease and the rise of chloroquine resistance," Current Opinion in Infectious Diseases, vol. 22, no. 5, pp. 430-435, 2009.

[48] I. H. Cheeseman, B. A. Miller, S. Nair et al., "A major genome region underlying artemisinin resistance in malaria," Science, vol. 335, no. 6077, pp. 79-82, 2012.

[49] F. O. Ter Kuile, A. M. van Eijk, and S. J. Filler, "Effect of sulfadoxine-pyrimethamine resistance on the efficacy of intermittent preventive therapy for malaria control during pregnancy: a systematic review," The Journal of the American Medical Association, vol. 297, no. 23, pp. 2603-2616, 2007.

[50] R. N. Price, A.-C. Uhlemann, M. van Vugt et al., "Molecular and pharmacological determinants of the therapeutic response to artemether-lumefentrine in multidrug-resistant Plasmodium falciparum malaria," Clinical Infectious Diseases, vol. 42, no. 11, pp. 1570-1577, 2006.

[51] R. M. Packard, "The origins of antimalarial-drug resistance," New England Journal of Medicine, vol. 371, no. 5, pp. 397-399, 2014.

[52] K. Marsh, "Malaria disaster in Africa," Lancet, vol. 352, no. 9132, p. $924,1998$.

[53] E. L. Korenromp, B. G. Williams, E. Gouws, C. Dye, and R. W. Snow, "Measurement of trends in childhood malaria mortality in Africa: An assessment of progress toward targets based on verbal autopsy," Lancet Infectious Diseases, vol. 3, no. 6, pp. 349358, 2003.

[54] D. F. Clyde and G. T. Shute, "Resistance of Plasmodium falciparum in Tanganyika to pyrimethamine administered at weekly intervals," Transactions of the Royal Society of Tropical Medicine and Hygiene, vol. 51, no. 6, pp. 505-513, 1957.

[55] I. Petersen, R. Eastman, and M. Lanzer, "Drug-resistant malaria: molecular mechanisms and implications for public health," FEBS Letters, vol. 585, no. 11, pp. 1551-1562, 2011.

[56] M. A. Travassos and M. K. Laufer, "Resistance to antimalarial drugs: molecular, pharmacologic, and clinical considerations," Pediatric Research, vol. 65, no. 5, article 2, pp. 64R-70R, 2009.

[57] A. Nzila, E. Ochong, E. Nduati et al., "Why has the dihydrofolate reductase 164 mutation not consistently been found in Africa yet?" Transactions of the Royal Society of Tropical Medicine and Hygiene, vol. 99, no. 5, pp. 341-346, 2005.
[58] J. C. Wootton, X. Feng, M. T. Ferdig et al., "Genetic diversity and chloroquine selective sweeps in Plasmodium falciparum," Nature, vol. 418, no. 6895, pp. 320-323, 2002.

[59] T. E. Wellems and C. V. Plowe, "Chloroquine-resistant malaria," Journal of Infectious Diseases, vol. 184, no. 6, pp. 770-776, 2001.

[60] J. G. Kublin, J. F. Cortese, E. M. Njunju et al., "Reemergence of chloroquine-sensitive Plasmodium falciparum malaria after cessation of chloroquine use in Malawi," Journal of Infectious Diseases, vol. 187, no. 12, pp. 1870-1875, 2003.

[61] M. D. Spring, J. T. Lin, J. E. Manning et al., "Dihydroartemisinin-piperaquine failure associated with a triple mutant including kelch13 C580Y in Cambodia: An observational cohort study," The Lancet Infectious Diseases, vol. 15, no. 6, pp. 683-691, 2015.

[62] R. Leang, A. Barrette, D. M. Bouth et al., "Efficacy of dihydroartemisinin-piperaquine for treatment of uncomplicated plasmodium falciparum and plasmodium vivax in Cambodia, 2008 to 2010," Antimicrobial Agents and Chemotherapy, vol. 57, no. 2, pp. 818-826, 2013.

[63] B. Witkowski, V. Duru, N. Khim et al., "A surrogate marker of piperaquine-resistant Plasmodium falciparum malaria: a phenotype-genotype association study," The Lancet Infectious Diseases, vol. 17, no. 2, pp. 174-183, 2017.

[64] S.-M. Zhao and M.-Y. Wang, "Artemisinin resistance in Plasmodium falciparum: global status and basic research," Chinese journal of parasitology \& parasitic diseases, vol. 32, no. 5, pp. 380-384, 2014.

[65] R. M. Fairhurst, G. M. L. Nayyar, J. G. Breman et al., "Artemisinin-resistant malaria: research challenges, opportunities, and public health implications," The American Journal of Tropical Medicine and Hygiene, vol. 87, no. 2, pp. 231-241, 2012.

[66] T. Mita and K. Tanabe, "Evolution of Plasmodium falciparum drug resistance: Implications for the development and containment of artemisinin resistance," Japanese Journal of Infectious Diseases, vol. 65, no. 6, pp. 465-475, 2012.

[67] C. O’Brien, P. P. Henrich, N. Passi, and D. A. Fidock, "Recent clinical and molecular insights into emerging artemisinin resistance in Plasmodium falciparum," Current Opinion in Infectious Diseases, vol. 24, no. 6, pp. 570-577, 2011.

[68] C. Wongsrichanalai and C. H. Sibley, "Fighting drug-resistant Plasmodium falciparum: The challenge of artemisinin resistance," Clinical Microbiology and Infection, vol. 19, no. 10, pp. 908-916, 2013.

[69] L. R. Johnson, K. D. Lafferty, A. McNally et al., "Mapping the Distribution of Malaria: Current Approaches and Future Directions," in Analyzing and Modeling Spatial and Temporal Dynamics of Infectious Diseases, D. Chen, B. Moulin, and W. J. Hoboken, Eds., pp. 189-209, John Wiley \&a Sons, NJ, USA, 2015.

[70] H. Noedl, "The need for new antimalarial drugs less prone to resistance," Current Pharmaceutical Design, vol. 19, no. 2, pp. 266-269, 2013.

[71] World Health Organization, Strategy for malaria elimination in the Greater Mekong Subregion: 2015-2030, 2015, http://iris.wpro .who.int/bitstream/handle/10665.1/10945/9789290617181_eng .pdf? sequence $=1$.

[72] M. Imwong, T. Jindakhad, C. Kunasol, K. Sutawong, P. Vejakama, and A. M. Dondorp, "An outbreak of artemisinin resistant falciparum malaria in Eastern Thailand," Scientific Reports, vol. 5, article no. 7412, 2015. 
[73] S. Takala-Harrison, C. G. Jacob, and C. Arze, "Independent emergence of artemisinin resistance mutations among Plasmodium falciparum in Southeast Asia," The Journal of Infectious Diseases, vol. 211, no. 5, pp. 670-679, 2015.

[74] R. L. Summers, M. N. Nash, and R. E. Martin, "Know your enemy: Understanding the role of PfCRT in drug resistance could lead to new antimalarial tactics," Cellular and Molecular Life Sciences, vol. 69, no. 12, pp. 1967-1995, 2012.

[75] E. Pelfrene, M.-H. Pinheiro, and M. Cavaleri, "Artemisininbased combination therapy in the treatment of uncomplicated malaria: review of recent regulatory experience at the European Medicines Agency," International Health, vol. 7, no. 4, pp. 239246, 2015.

[76] World Health Organization, Overview of malaria treatment, 2016, http://www.who.int/malaria/areas/treatment/overview/ en/.

[77] A. A. A. Elmannan, K. A. Elmardi, Y. A. Idris, J. M. Spector, N. A. Ali, and E. M. Malik, "Anti-malarial prescribing practices in Sudan eight years after introduction of artemisinin-based combination therapies and implications for development of drug resistance," BMC Pharmacology and Toxicology, vol. 16, no. 1, article no. 3, 2015.

[78] S. Berendes, O. Adeyemi, E. A. Oladele, O. B. Oresanya, F. Okoh, and J. J. Valadez, "Are Patent Medicine Vendors Effective Agents in Malaria Control? Using Lot Quality Assurance Sampling to Assess Quality of Practice in Jigawa, Nigeria," PLoS ONE, vol. 7, no. 9, Article ID e44775, 2012.

[79] N. Mishra, R. Gupta, S. Singh et al., "Insights following change in drug policy: A descriptive study for antimalarial prescription practices in children of public sector health facilities in Jharkhand state of India," Journal of Vector Borne Diseases, vol. 50, no. 4, pp. 271-277, 2013.

[80] V. S. Pribluda, L. Evans, E. Barillas, J. Marmion, P. Lukulay, and J. Chang, "Were medicine quality and pharmaceutical management contributing factors in diminishing artemisinin efficacy in Guyana and Suriname?" Malaria Journal, vol. 13, no. 1, article no. 77, 2014.

[81] O. Miotto, J. Almagro-Garcia, M. Manske et al. et al., "Multiple populations of artemisinin-resistant Plasmodium falciparum in Cambodia," Nature Genetics, vol. 45, no. 6, pp. 648-655, 2013.

[82] E. Talundzic, S. A. Okoth, K. Congpuong et al. et al., "Selection and spread of artemisinin-resistant alleles in Thailand prior to the global artemisinin resistance containment campaign," PLoS Pathog, vol. 11, no. 4, Article ID e1004789, 2015.

[83] W. M. Sweileh, "Global research trends of World Health Organization's top eight emerging pathogens," Globalization and Health, vol. 13, no. 1, 2017.

[84] W. M. Sweileh, S. W. Al-Jabi, A. F. Sawalha, A. S. AbuTaha, and S. H. Zyoud, "Bibliometric analysis of publications on Campylobacter: (2000-2015)," Journal of Health, Population and Nutrition, vol. 35, no. 1, 2016.

[85] W. M. Sweileh, S. W. Al-Jabi, A. F. Sawalha, A. S. AbuTaha, and S. H. Zyoud, "Bibliometric analysis of medicine-related publications on poverty (2005-2015)," SpringerPlus, vol. 5, no. 1, article no. $1888,2016$.

[86] W. M. Sweileh, A. F. Sawalha, S. Al-Jabi, and S. H. Zyoud, "Bibliometric analysis of literature on antifungal triazole resistance: 1980 - 2015," GERMS, vol. 7, no. 1, pp. 19-27, 2017.

[87] W. M. Sweileh, A. F. Sawalha, S. W. Al-Jabi, S. H. Zyoud, N. Y. Shraim, and A. S. Abu-Taha, "A bibliometric analysis of literature on malaria vector resistance: (1996 - 2015)," Globalization and Health, vol. 12, no. 1, article no. 76, 2016.
[88] W. M. Sweileh, N. Y. Shraim, S. W. Al-Jabi, A. F. Sawalha, A. S. AbuTaha, and S. H. Zyoud, "Bibliometric analysis of global scientific research on carbapenem resistance (1986-2015)," Annals of Clinical Microbiology and Antimicrobials, vol. 15, no. 1, article no. 56, 2016.

[89] S. Zyoud, W. Waring, S. Al-Jabi, and W. Sweileh, "Global research production in glyphosate intoxication from 1978 to 2015: A bibliometric analysis," Human \& Experimental Toxicology.

[90] S. H. Zyoud, W. S. Waring, S. W. Al-Jabi, and W. M. Sweileh, "Global cocaine intoxication research trends during 1975-2015: a bibliometric analysis of Web of Science publications," Substance Abuse Treatment, Prevention, and Policy, vol. 12, no. 1, 2017. 


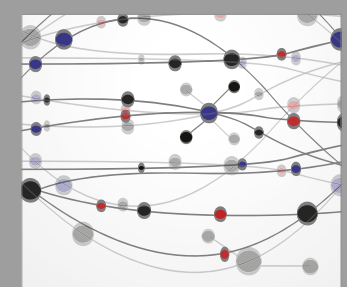

The Scientific World Journal
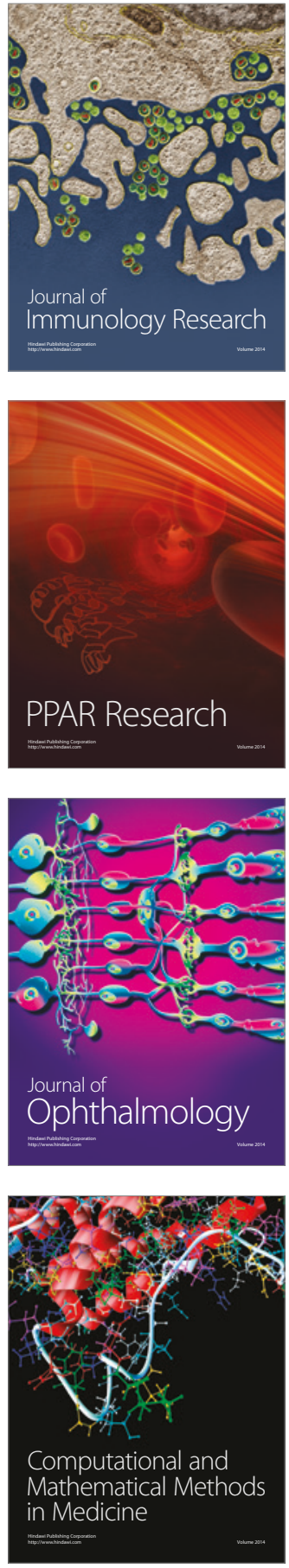

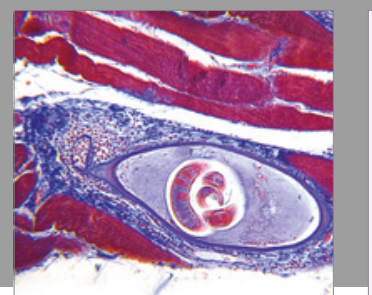

Gastroenterology Research and Practice
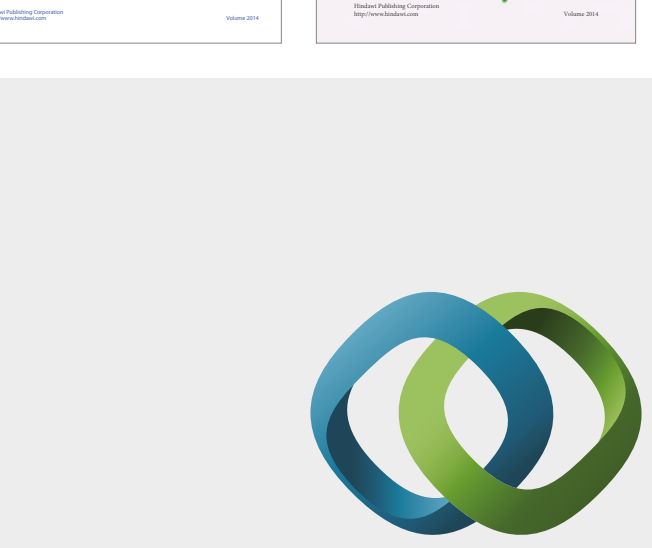

\section{Hindawi}

Submit your manuscripts at

https://www.hindawi.com
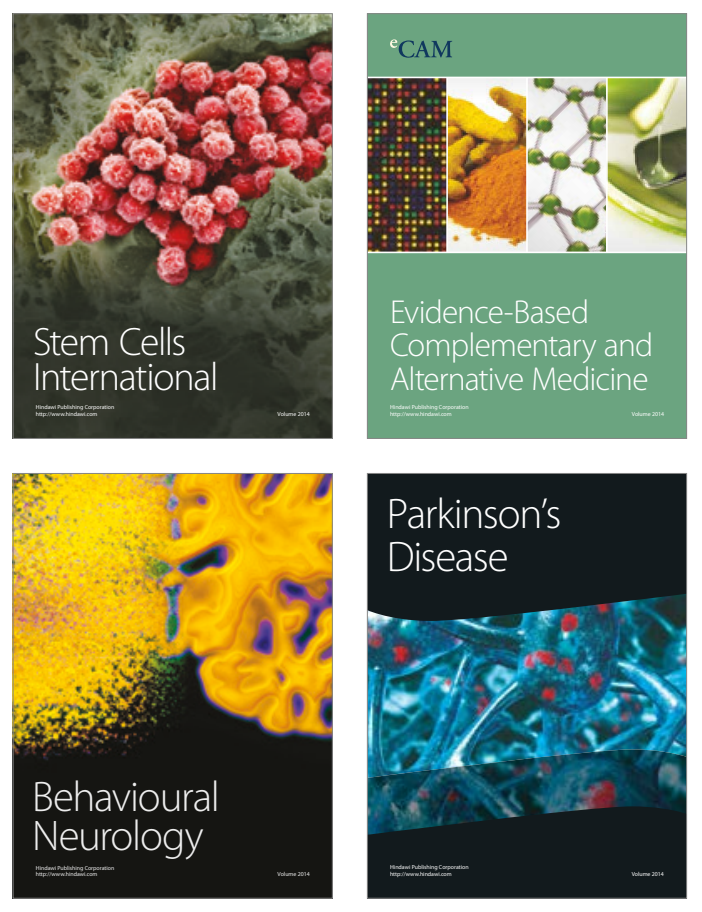
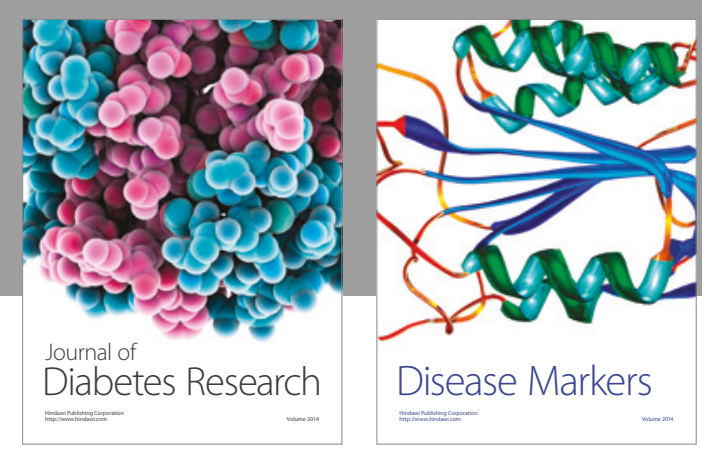

Disease Markers
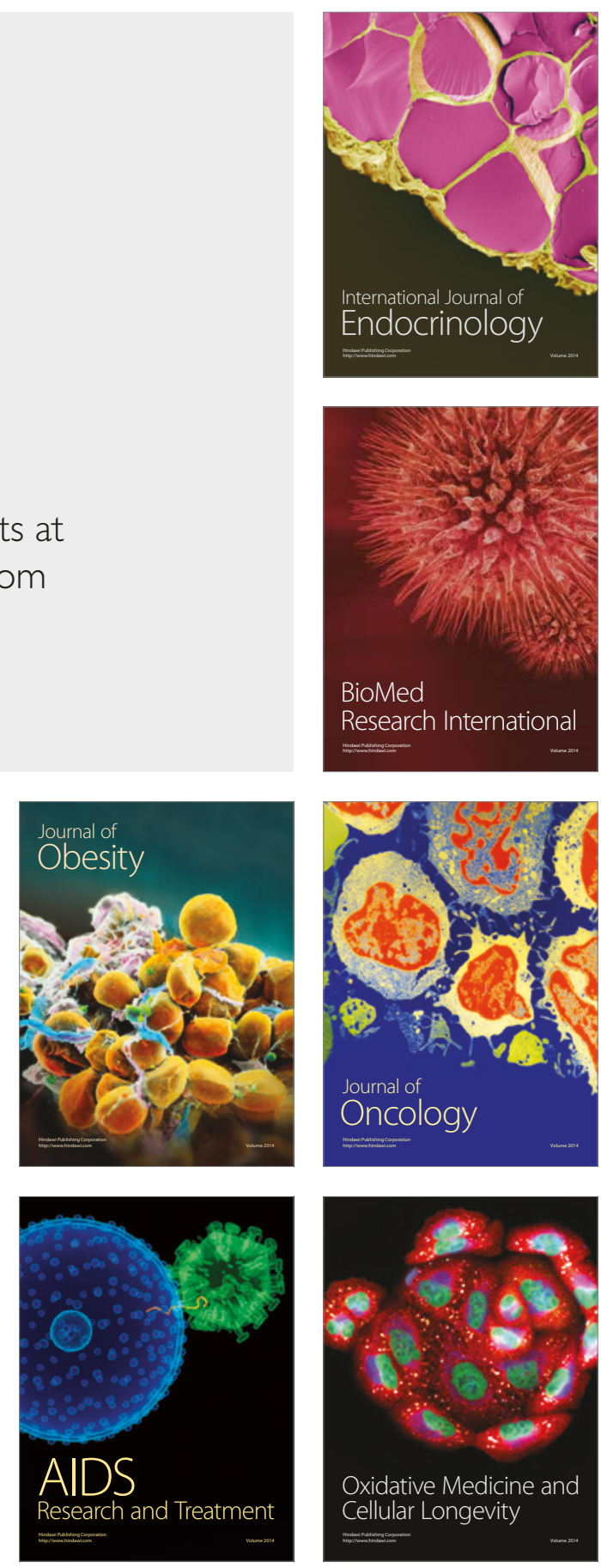